\title{
The research of the stereoscopic characteristics of virtual reality helmets
}

\author{
A.I. Vinokur ${ }^{1, A}$, N.V. Kondratiev²,B, Yu.N. Ovechkiss,A \\ A Moscow Polytechnic University \\ B Branch office "NIKFI" JSC TP "Film Studio. M. Gorky" \\ 1 ORCID: 0000-0002-6914-2520, alex.vinokour@gmail.com \\ 2 ORCID: 00oo-0001-6717-8661, kondr1216@mail.ru \\ 3 ORCID: 00oo-0003-2325-0857, ovechkis@yandex.ru
}

\begin{abstract}
Individual stereoscopic virtual reality devices have become very popular all over the world. Their advantages in comparison with traditional means of presenting stereo images are to provide a large viewing angle, taking into account the location and movement of the observer, binding the image to the direction of his gaze. To obtain a high-quality and comfortable visualization system, it is necessary to achieve a certain ratio of technical parameters. In this paper, we consider the limitations of the depth of a three-dimensional image reproduced in helmets of virtual and augmented reality, due to the stereoscopic nature of its formation. Methods and results of the estimated calculations of the boundary distances for different conditions for the demonstration of three-dimensional stereoscopic images are given. Experimental studies of the overall parameters of optical circuits of seven different types of virtual reality helmets have been carried out. It is shown that most of them, especially the most accessible as cheaper and often used in a social environment, are not suitable for demonstrating deep scenes of the surrounding visual environment. Recommendations for their modernization are given.
\end{abstract}

Keywords: stereoscopy, virtual reality, accommodation, convergence, 3D, virtual reality helmet.

\section{Introduction}

The interest in stereoscopic (or as it was called 3D) cinematography, and then in television with stereoscopic effect, which appeared at the beginning of the last decade, has considerably decreased $[1,2]$. With few exceptions, the film industry has practically abandoned the creation of stereo products and television receivers have been manufactured mainly without the $3 \mathrm{D}$ option. One of the reasons for such a decline, but not the only one, is the discomfort that often appears in viewers while watching stereoscopic video - headaches, nausea, eye carving, ailments, etc. These issues are the result of either not enough competent consideration of the peculiarities of shooting and demonstration of stereoscopic image, or ignoring them, or errors in the layout of the stereo series [3].

The devices of virtual reality have appeared several years ago in various implementations helmets, glasses, etc. They are still in great demand both in the social sphere - attractions, exhibitions, museums, etc., and in the scientific and technical field - simulators, training systems, scientific visualization. The interest is caused by the appearance of new functionalities of this type of stereoscopic devices - a large angle of view, up to 360 degrees, the binding of the three-dimensional image to the direction of the observer's gaze, and in a number of implementations and its location and movement in space, the ability to interact with other virtual or real objects. The requirements to the generated image in such devices are clearly much 
stricter than in stereoscopic cinematography or television. The system is adaptive and in addition to the need to comply with the requirements imposed by the stereoscopic nature of the video sequence, there are also requirements for the speed of feedback, i.e. compliance with the position of the observer and the direction of his eyes at every moment of time.

Thus the factors leading to possible discomfort become more significant.

Therefore in order for virtual and augmented reality devices not to suffer the fate of stereoscopic cinematography and television, the above requirements must be strictly observed. This work is devoted to the consideration and formulation of requirements for stereoscopic characteristics of the formed three-dimensional image in virtual reality devices of different purposes. In addition an experimental study of the stereoscopic capabilities of virtual reality helmets has been carried out, and as a result there are recommendations for their modernization.

\section{Analysis of the stereoscopic properties of virtual reality helmets}

The general approach to the estimation of the influence of stereoscopic character of the $3 \mathrm{D}$ image formation in the helmets of virtual reality on the depth of the reproduced space is considered in work [4]. The optical scheme of the virtual reality helmet is analyzed (Fig. 1), which repeats the simplest stereoscope in its construction and functional elements [5]. Two angles of the displayed visual environment are formed on the $\vartheta_{1}$ and $\vartheta_{2}$ screens, located at some distance from the $\Omega_{1}$ and $\Omega_{2}$ lenses, through which the perceived three-dimensional stereoscopic image is considered.

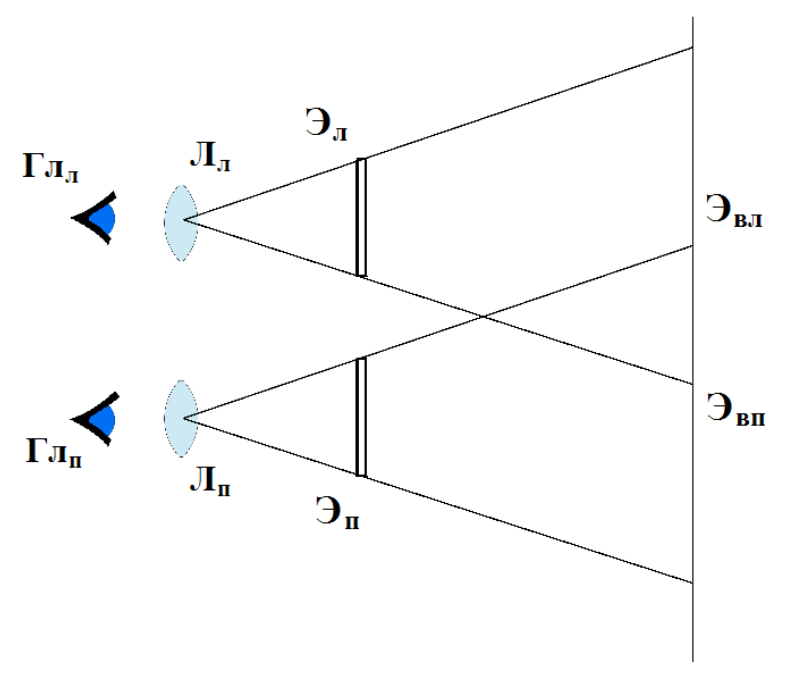

Fig. 1. Principal optical scheme of the virtual reality helmet

The distance $\mathrm{L}$ from the lenses (actually from the eyes of $Г л_{л}$ and $Г л_{\Pi}$ ) to the virtual screens of

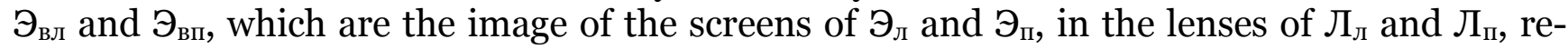
spectively, is determined by their focal length $f$, the distance $l$ from the lenses to the screens and is calculated by the known formula of the lens [6]:

$$
1 / L=1 / l-1 / f
$$

The distance $\mathrm{L}$ to the virtual screen that displays flat images of the right and left angles of the visual environment is in fact a definition for the assessment of the possible depth of stereoscopic $3 \mathrm{D}$ image, perceived calmly and without various painful sensations.

In addition to various technological factors leading to possible discomfort when viewing stereoscopic images, there is a vertical parallax, excessive positive horizontal parallaxes, confused angles, etc. $[5,7,8]$.This variable can be eliminated at the stage of creating a video sequence, the main negative role is played by the so-called gap between accommodation and 
convergence [5, 7]. This gap is due to the fact that eye accommodation, i.e. focusing, is always carried out on the screen plane, in this case virtual, and the reduction of the optical axes of the eyes - convergence, is made on the considered element of the $3 \mathrm{D}$ image, located, in general, outside the screen. This characteristic $\Delta$ is calculated as an absolute value of the difference between the angles of optical eye axes when observing the image element located in the plane of the screen $\alpha_{a k}$ (accommodation angle) and outside it - $\alpha_{a k o n}$ (convergence angle):

$$
\Delta=/ \alpha_{\text {ак }}-\alpha_{\text {кон }} /
$$

Clearly that the greater the depth of the stereoscopic space that is perceived, the greater the size of the space and the greater the risk of pain in viewing. There are limits to the gap between accommodation and convergence for comfortable viewing. For various applications of stereoscopic reproducing systems and comfort requirements, the range of changes in this value ranges from $16-32^{\prime}[9,10]$ to $70-110^{\prime}[5]$. The first range is tougher and provides almost no discomfort during viewing. This restriction should be taken into account when developing devices for children, creating stereoscopic manuals, etc. The second range is less rigid - short-term small discomfort sensations are possible in various attractions, shows, etc., it is the range that is accepted in stereoscopic cinematography.

Distances to the near and far borders of the area in which the stereoscopic image is perceived quite comfortably according to [5] are defined as the field depth limits of view for the observer's eyes focused on the screen plane, in our case the virtual one on which the angles are formed. The angular resolution of the eye $\delta$, chosen to determine this sharpness, characterizes the above ranges of accommodation and convergence rupture. In accordance with [4, 10], expressions (3) are used to find distances to the borders of the observed comfortably stereoscopic image, and the dependence of the accepted angular resolution of the eye with the value of the gap between accommodation and convergence determines the expression (4):

$$
\begin{array}{rlr}
L_{1} & =\frac{L d}{d+L \delta}, & \\
L_{2} & =\frac{L d}{d-L \delta} \quad & \text { when } d \geq L \delta, \\
L_{2} & =\infty, & \text { when } d \leq L \delta, \\
\Delta \approx B \delta / d \approx 16 \delta &
\end{array}
$$

$L_{1,2}$ - the distance to the nearest and farthest area borders of stereo image comfortable perception, $B$ - the eye base $(65 \mathrm{~mm}), d$ - the diameter of the eye pupil ( $4 \mathrm{~mm})$.

As it can be seen from equations, the depth of the stereoscopic space perceived without stress depends significantly on the value of $L$, the distance to the virtual screen, and $\delta$, the chosen angular resolution, which determines the acceptable gap between accommodation and convergence. It is therefore clear that the optical calculation of the virtual reality helmets should be based on its purpose, i.e. the required depth and distance to it, and the user population. Fig. 2 shows the graphs of dependences $L_{1}$ - upper curves and $L_{2}$ - lower curves of the distance $L$ for two characteristic values of angular resolution $\delta$. The value $\delta=2$ ', which is close to the eye resolution limit of $1^{\prime}$ [11], determines the minimum value $\Delta=32$, which is sufficient to make undesirable painful sensations during viewing whole depth of stereoscopic space practically absent. As noted above this condition is necessary where the complete lack of possible painful sensations is critical - use in childhood and school age, in educational devices, etc. A value of $\delta=6^{\prime}$, corresponding to $\Delta=96$ ', can be used with less stringent restrictions, similar to those adopted when creating a video sequence in stereoscopic cinematography. 


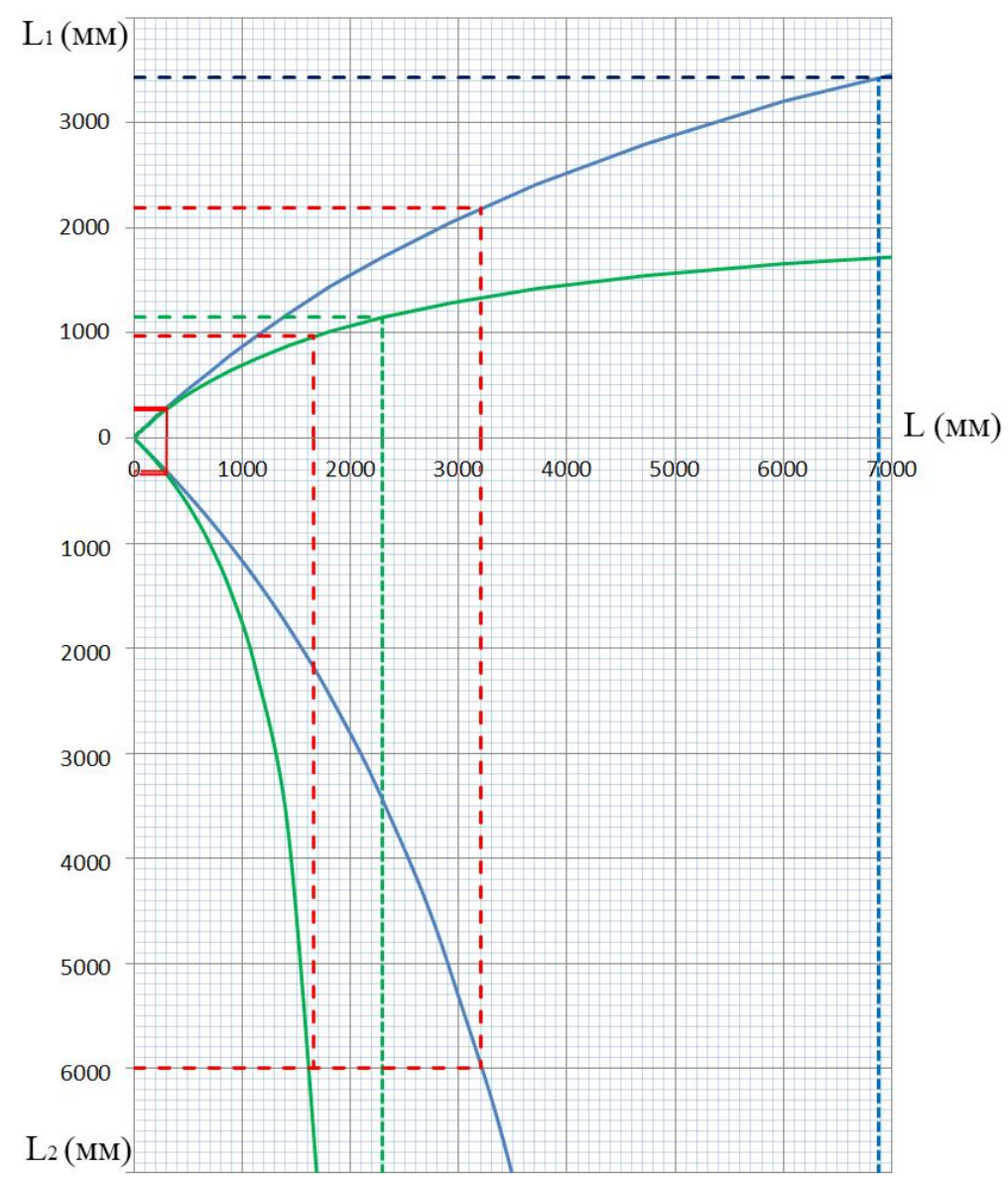

Fig. 2. Graphs of dependencies $\mathrm{L}_{1}$ - upper curves and $\mathrm{L}_{2}$ - lower curves from the distance $\mathrm{L}$ to the virtual screen. The blue color shows the dependencies for $\delta=2^{\prime}$, the green color $-\delta=6^{\prime}$.

Vertical asymptotes to the lower parts of the chart are represented by the dotted line of blue and green colors respectively. Their intersection with the L-axis determines the minimum distance to the virtual screen, at which the distance to the far edge of the comfort area goes into infinity. For the selected values of $\delta$ equal to $2^{\prime}$ and $6^{\prime}$ we have $\mathrm{L}_{2}=6.9 \mathrm{~m}$ and $\mathrm{L}_{2}=2.3 \mathrm{~m}$ respectively.

At the same time the distances $\mathrm{L}_{1}$ to the nearest border of the comfort zone according to (3) are half as small and has $\mathrm{L}_{1}=3.45 \mathrm{~m}$ and $\mathrm{L}_{1}=1.15 \mathrm{~m}$, respectively. These parameters are optimal for virtual reality helmets designed to display objects of visual environment located at long distances, up to infinity, for example for aircraft simulators. Increasing the distance to the virtual screen will increase the distance to the near edge of the comfort zone.

For short distances to the virtual screen, as can be clearly seen (Fig. 2), the depth of the stereoscopic space is extremely small and grows rapidly with distance increase. These curves allow us to formulate the initial conditions for the calculation of the optical scheme overall parameters of the virtual reality helmet. If the helmet is intended to demonstrate far objects with a maximum distance to them, for example, $6 \mathrm{~m}$, then through this point on the lower axis of ordinates (Fig. 2) should be drawn a horizontal line up to the intersection of the curve under consideration and through the resulting intersection point a vertical line. The intersection point with the abscissa axis will indicate the necessary distance to the virtual screen. The distance between the helmet lenses and the display screens (Fig. 1) is calculated by formula (1). The intersection with the upper curve determines the distance to the nearest border of the area of space to be perceived comfortably. In our case, for $\delta=2^{\prime}$ and $\delta=6^{\prime}$, the optimal distances from the lenses to the virtual screen are $3.2 \mathrm{~m}$ and $1.7 \mathrm{~m}$, respectively, and the distances to the nearest boundary of the stereoscopic image are $2.2 \mathrm{~m}$ and $1.0 \mathrm{~m}$. The geometric constructions of the given process are highlighted in Fig. 2 with dotted red lines. 
Similar constructions should be performed in reverse order, if the near border of the stereoscopic image area is critical without tension. Clearly it is not always possible to achieve the desired results for the near and far borders of this area at the same time. In such cases it is necessary to look for a compromise solution and either limit its size or allow some violations of the restrictions.

Note also that the above reasoning gives estimated results and requires additional analysis, because there are secondary factors of discomfort associated with the peculiarities of the video sequence itself, its dynamics, smooth movement of objects in depth, their mutual position in space, duration of the demonstration, etc. 4, 9], which may impose additional restrictions on the depth of the stereoscopic image.

\section{The experimental search of optical parameters for the virtual reality helmets}

Currently there is a wide variety of virtual reality helmets on sale, both simple and cheap (from hundreds to several thousand rubles), designed primarily to work with smartphones, and more expensive and complex devices, with some adjustments and with built-in screens costing from tens to several hundred thousand rubles. However, the accessible documentation on these devices in the majority does not contain data on dimensional characteristics of optical schemes and in particular on an arrangement distance of the virtual screen. Accounting this parameter plays an important role in the appearance of undesirable sensations when viewing stereoscopic video was provide the optical parameters experimental research of the virtual reality helmets, both cheap and more expensive. At the same time, more attention was paid to the cheapest samples as the most accessible and, accordingly, more widely used ones. For the experimental measurement of the distance from the lenses to the location of the virtual screen was collected installation, schematically depicted in Fig. 3. On the optical axis one of the lenses (in this case for the left eye) $\Omega_{л}$ helmet $\amalg$ at some distance from it was a reference lens $J_{3}$ with a known focal length $F$, after which was installed a scattering light screen $\exists_{\mathrm{p}}$. The measuring lens and screen were able to move along the optical axis. The image of the bar contrast test object was formed with PC and was translated to the corresponding screen of the display Дл. For helmets in which could be placed smartphone a similar image was displayed on the screen.

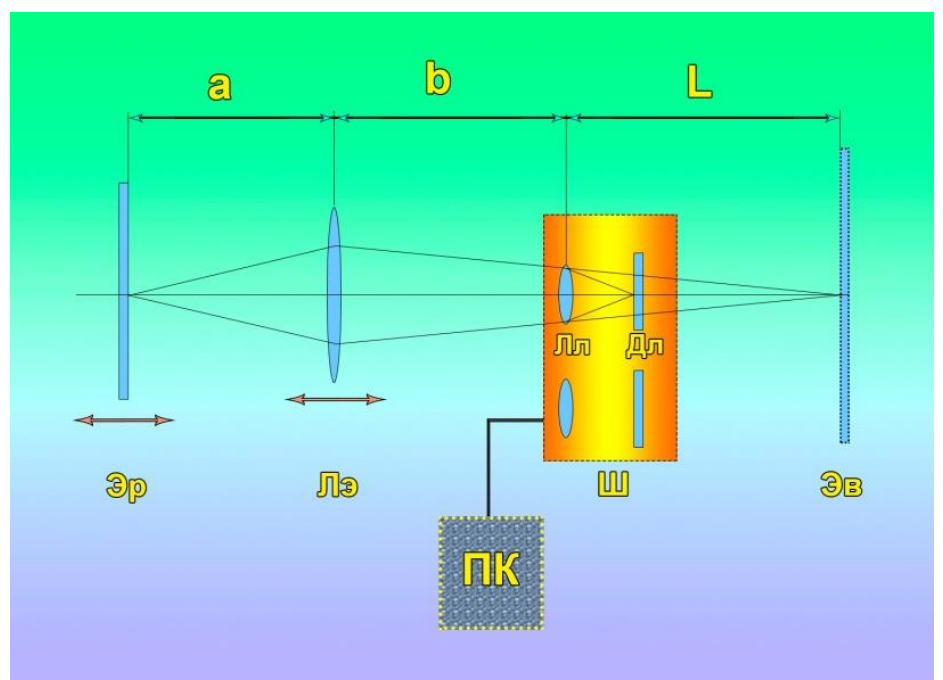

Fig. 3. Basic installation diagram for distance measurement to the virtual screen

The $\pi_{\ni}$ reference lens has been moved sequentially along the optical axis, occupying several fixed discrete positions relative to the helmet. For each of them, the $\exists_{\mathrm{p}}$ screen was set up at the best focusing point for the image of the test object determined visually by a magnifier. Then the distances between the reference lens and the screen $(a)$ and one of the helmet lenses 
(в) were measured. The distance $L$ from the helmet lens to the location of the $\vartheta_{\mathrm{B}}$ virtual screen was determined by the lens formula with subsequent averaging:

$$
\begin{aligned}
& L i=a F /(a-F)-b \\
& L=1 / n \sum_{i=1}^{n} L i
\end{aligned}
$$

where $\mathrm{n}=5$ number of measurements.

Seven samples of virtual reality helmets were selected for measurements. Three helmets from the low-cost segment that work in connection with a smartphone are Ritech Riem3, Qilive Max and VR Shinecon. The last two samples had the possibility of changing the distance to the display, so two sets of measurements were made for them - for the near and farther location of the virtual screen. The two helmets are relatively expensive, the Oculus Rift DK-2 and Display Systems i-glasses 3D. An experimental helmet sample was also researched to display the external visual environment of the ESHVO1 and the FXT Viper $5.8 \mathrm{GHz}$ helmet (glasses), designed to work as a video recorder in conjunction with a radio-controlled quadcopter. Note that the available documentation for all but one of these devices, Display Systems i-glasses $3 \mathrm{D}$, does not contain information about the location of the virtual screen.

The results of the measurements are shown in Table 1. It is easy to see that except for the two samples, the fourth and fifth in the table, all helmets are designed in such a way that the distance from the lenses (observer's eyes) to the virtual screen, on which the images of the two angles are formed, does not exceed $370 \mathrm{~mm}$. At such small values of distance $L$ the depth of comfortably perceived space according to formulas (3) and diagrams in Fig. 2 will make only $140 \mathrm{~mm}$ for less strict criterion, and $50 \mathrm{~mm}$ for rigid restriction.

Table 1

\begin{tabular}{|l|l|l|l|}
\hline № & Helmet name BP & $\begin{array}{l}\text { Distance to virtual screen } \\
L(\mathrm{~mm})\end{array}$ & Note \\
\hline 1 & Ritech Riem3 & 360 & Adjustment option \\
\hline \multirow{2}{*}{2} & Qilive Max & 360 & \multirow{2}{*}{ Adjustment option } \\
\cline { 2 - 4 } 3 & VR Shinecon & 370 & \\
\cline { 2 - 4 } & & 170 & $\begin{array}{l}\text { Data from technical } \\
\text { documentation }\end{array}$ \\
\hline 5 & $\begin{array}{l}\text { Oculus Rift DK-2 } \\
\text { 3D }\end{array}$ & 1600 & Experimental sample \\
\hline 6 & ЭWBO1 Systems i-glasses & 4000 & $\begin{array}{l}\text { Glasses for quadrupter } \\
\text { operation }\end{array}$ \\
\hline 7 & FXT Viper $5.8 \mathrm{GHz}$ & 300 & \\
\hline
\end{tabular}

At the same time the descriptions and technical characteristics of the helmets sold do not contain information about needs to limit the depth of the reproduced stereoscopic image of virtual reality anywhere, while it is the deep scenes which are significantly beyond the marked limits due to the effectiveness impact on observers are usually demonstrated at home and in small attractions. It is the helmets similar to the first three in Table 1, that are particularly popular with young people and teenagers because of their ease of use - their ability to use a smartphone - and their affordable price, and that often ignore some of the signs of discomfort that can lead to unwanted complications. Therefore one of the most important goals of this article is to pay special attention to the peculiarities of stereoscopic formation $3 \mathrm{D}$ image and to the associated risk of pain during viewing and subsequent complications.

Optical parameters of the remaining two helmets allow to observe painlessly stereoscopic image in a sufficiently large range of depths, corresponding to the curves shown in Fig. 2. As for the helmet under the fifth number in the table, the observed image is flat without stereoscopic effect and is formed by a mono screen with the help of an aspherical mirror at a small dis- 
tance (300 mm) from the observer's eyes. Accordingly there is no gap between accommodation and convergence in it. However, taking into account its purpose - control of the quadcopter and reading video information from it, it would be more expedient to take this image to infinity and make the process of control and viewing more natural and quiet, as it is done in aircraft simulators.

Accounting above mentioned problems related to the peculiarities of stereoscopic images demonstration, when buying virtual reality helmets one should be interested in the location of the virtual screen. In the absence of such information measurements similar to the above should be made. If necessary and if it is structurally possible to use smartphones as an image source for inexpensive helmets, they can be upgraded. For this purpose it is necessary to increase the distance between the lenses $\Omega_{1}, \Omega_{2}$ and the screen of the smartphone $Д$ (Fig. 1), move the last by a small distance determined experimentally using the above methods and scheme of measurement (Fig. 4). The test image should be displayed on the screen near the focus of the $Л_{и}$ lens. The angle of view will be slightly reduced so a compromise must be found between the quality of the stereoscopic image and the degree of its realism. Clearly such upgrade of the helmet will require further development of the helmet, connected with the reconstruction of the rear wall of the device.

\section{Conclusion}

The following conclusions and recommendations can be drawn from the analysis and research.

1. The distance from the observer's eyes to the formation place of the virtual screen in the helmet of virtual reality plays a decisive role in determining the depth of the comfortably perceived stereoscopic space and the distance to it. Are given analytical and graphical data for calculation of these values and examples of their use.

2. Experimental studies of real and affordable virtual reality helmets have shown that for most of them the during demonstration deep $3 \mathrm{D}$ scenes can cause painful feelings, which are unacceptable especially for users children and school age.

3. Recommendations to upgrade virtual reality helmets to improve their display properties are given.

\section{References}

1. Augmented Reality and Virtual Reality Market by Offering (Hardware \& Software), Device Type (HMD, HUD, Handheld Device, Gesture Tracking), Application (Enterprise, Consumer, Commercial, Healthcare, Automotive), and Geography -Global Forecast to 2023 (2018)//Markets and Markets.

URL: https://www.marketsandmarkets.com/Market-folder/virtual-and-augmentedreality/report.pdf.

2. Leo H. Bräutigam: eBook, 3D-Fotografie - 3D-Video, Civitas Imperii Verlag Esslingen, 2014, ISBN 978-3-939300-28-1

3. N.N Krasilnikov. Vliyanie rasstoyaniya nabliudeniya na glubinu prostranstva, vosproizvodimuyu stereoskopicheskim izobrageniem. Opticheskii gurnal// Sankt-Peterburgskii natsionalnii issledovatelskii universitet informatsionnikh tehnologii, mehaniki i optiki. (Sankt-Peterburg), issn: 1023-5086 [in Russian].

4. Yu.N. Ovechkis, D.I. Popov, A.I. Romanova. Analiz vliyaniya razriva megdu akkomodatsiei I konvergentsiei v shlemah virtualinoi realnosti na komphortnosti vospriiatia//Mir Tehniki Kino.-2016.-№4-S.3 - 6 [in Russian].

5. N.A. Valius Stero Photographiya Stereokino Stereotelevideniye // M.: Iskusstvo.- 1986..262 s. [in Russian].

6. G.S. Landsberg Optica // M. Nauka 1976928 s. [in Russian]

7. S.N. Rogkov, N.A. Ovsianikova. Stereoskopiya v kino-, photo-, videotekhnike: terminologicheskii slovari// M. Paradiz/- 2003.- 135 s. [in Russian]. 
8. V.A. Liudvichenko, S.V. Lavrushkin, V.A. Ianushkovskii, D.S. Vatolin. Ovnarugenie vremennogo sdviga i pereputannogo poriadka rakursov d stereopfilmah.// Mir Tehniki Kino .- 2015.- №35 - S.10 - 13 [in Russian].

9. H. Lüscher Stereoskopische Tiefenzone und Tiefenscharfenzone des Auges // FotoKino Technik. 1947. № 6.

10. V.A. Elkhov, N.V. Kondratiev, Yu.N. Ovechkis, L.V. Pautova. Osobennosti formirovaniia obiyomnogo izobrageniya $\mathrm{v}$ tsifrovom stereoskopicheskom kinematographe// Mir Tehniki Kino.-2011.- №20 - S.4 - 8 [in Russian].

11. V.A. Panov, M.Ya. Kruger, V.V. Kulagin i dr. Spravochnik konstruktora optikomehanicheskih priborov. Pod obtch. red. V.A. Panova. - 3-e izd., pererab. i dop. - L.: Mashinostroeniie, 1980. - 742 s. [in Russian].

12. A.C. Melkumov. Faktori, vliiayutchie na discomfort i ustalosti pri prosmotre stereophilmov// Mir Tehniki Kino.- 2016.- №10 - S.31 -33 [in Russian]. 